\title{
Evaluation of Clinical \& Etiological Profile of Children with Seizures
}

\author{
Jagannath H. $\mathbf{N}^{1}$ \\ ${ }^{1}$ Associate professor, Department of Pediatrics, Akash Institute of Medical Sciences \& Research Centre, Bengaluru, Karnataka, India.
}

\section{Abstract}

Background: Seizures are a transient occurrence of signs and/or symptoms resulting from abnormal excessive or synchronous neuronal activity in the brain. Better understanding of seizures in terms of clinical presentation and etiology is required not only for abortion of acute attack but also for long term control of epilepsy. Subjects and Methods: This retrospective observational study included those children who were admitted with seizures within last 1 year time period of our study. Variables including age, sex, type of seizure, laboratory test results, neuroimaging, EEG findings, duration of hospital stay, diagnosis and final outcome were studied. Results: Incidence of seizures decreased with increasing age with less than 5 years age group most commonly involved. Generalized tonic clonic seizure were the most common type of seizure with febrile seizures being most common. etiology followed by CNS infections. Febrile seizures had best outcome while CNS infections had highest morbidity and mortality. Conclusion: We found CNS infections to be the most common etiology and a poor outcome. Acute episode of seizures is one of the commonest causes of hospitalization with high morbidity and mortality. Being a developing nation, strict measures to prevent infection can reduce the occurrence of seizures in children thus preventing long term neurological sequelae in children.

Keywords: Seizures, children, febrile seizures, CNS infections, developing nation.

Corresponding Author: Dr Jagannath H.N, Associate professor, Department of Pediatrics, Akash Institute of Medical Sciences \& Research Centre, Bengaluru, Karnataka, India.

Received: April 2020

Accepted: April 2020

\section{Introduction}

Seizures are a transient occurrence of signs and/or symptoms resulting from abnormal excessive or synchronous neuronal activity in the brain. ${ }^{[1]}$ They are common pediatric neurological disorders with highest incidence in children less than 3 years of age, with a decreasing frequency from then on and accounts for about $2 \%$ of all pediatric emergency department visits. ${ }^{[2]}$

The incidence of epilepsy (recurrent unprovoked seizures) in children and adolescents seems relatively consistent across all populations, ranging from 50 to $100 / 100$, 000 personyears. $^{[3]}$

Child-hood epilepsies are a heterogeneous group of conditions that differ in their diagnostic criteria and management and have dramatically different outcomes. Febrile seizures are considered most common type of seizures in children worldwide developing countries, and its been reported that Central nervous system (CNS) infections are the main cause of provoked seizures and acquired epilepsy in the developing world. ${ }^{[4]}$

Based on recent International League Against Epilepsy (ILAE) definition of epilepsy, ${ }^{[5]}$ we can diagnose epilepsy even after first episode of seizures if there is a probability of further seizures similar to the general recurrence risk at least $60 \%$ after two unprovoked seizures, occurring over the next 10 years. Usually non febrile patients are subjected to CT scan as first investigation. But some studies have shown that CT scan is not always required in these patients. Treating physicians have to decide for further investigations including septic screen, metabolic studies, lumbar puncture and electroencephalogram (EEG) for patients who present with a first attack of seizure. In a developing country like ours there is always a concern regarding cost and radiation exposure. ${ }^{[6]}$

Therefore, Better understanding of seizures in terms of clinical presentation and etiology is required not only for abortion of acute attack but also for long term control of epilepsy. Information regarding etiological profile of afebrile seizures is scarce, and there is paucity of data with the need for reaffirming awareness and knowledge regarding diagnostic variability and its presentations. Hence, the present study was undertaken to understand the clinicoetiological profile of seizures in chidren.

\section{Subjects and Methods}

This retrospective observational study was conducted in Department of Pediatrics. Medical records were observed of those children who were admitted with seizures within last 1 year time period of our study. Approval for the study was obtained from the institutional ethics committee (IEC).

The information regarding age (from 6 months to 18 years), sex, and type of seizure, no. of seizure episodes, with or 
without status epilepticus, associated symptoms (fever, headache, vomiting, altered sensorium), developmental history and family history of seizure or epilepsy were obtained.

Information of all laboratory investigations( complete blood count, blood glucose, serum electrolytes, cerebrospinal fluid (CSF) analysis, C- reactive proteins), Montoux test and all records of radiological investigations like Chest X-ray, , neuroimaging including CT scan head or cranial Magnetic Resonance Imaging (MRI), electroencephalography (EEG) and other tests were taken into account. Other parameters like duration of hospital stay, final diagnosis, and final outcome in five categories; discharged after recovery, discharged with deficits, left against medical advice, mortality and referral to other institutions were also recorded according to the study groups.

We classified seizures based on the Commission on Epidemiology and Prognosis, 2010 International League against Epilepsy (ILAE).7 This included generalized tonicclonic (GTC), absence, myoclonic, focal and other seizures types. Etiologies of seizures like meningitis and encephalitis were analyzed on the basis of clinical presentation and laboratory investigation and they were verified with standard reference textbooks.

\section{Statistical analysis:}

All the clinical, laboratory, radiological findings, and the follow-up data were collected and tabulated. They were analysed using Statistical Package for the Social Sciences (SPSS) for Windows Version 20.0 (SPSS Inc; Chicago, IL, USA). The Chi-square test and Fisher test were used to examine the association between different variables and strength of the relationship. $\mathrm{P}$ value less than 0.05 was considered as statistically significant.

\section{Results}

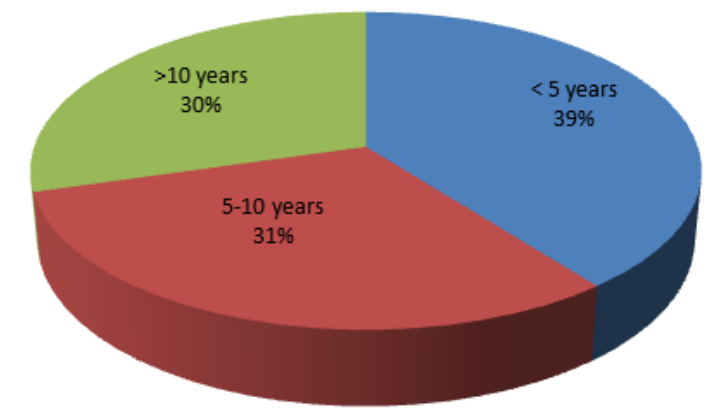

Figure 1: Case Distribution within Age Groups

A total of 200 patients were selected during the study period. Out of this $115(57.5 \%)$ were males and $85(42.5 \%)$ were females. Seizure occurrence was commonest in less than 5 yrs age group as compared to greater than 5 years with $79(39.5 \%)$ cases.

142 cases $(71 \%)$ had generalized seizures while 58 cases (29\%) had focal seizures. Generalized tonic clonic seizures were observed in $138(69 \%)$ cases, Tonic seizures in 40 (20\%) cases, Myoclonic seizures occurred in $16(8 \%)$ patients. While rest other types with less frequency occurred in $6(3 \%)$ patients.

Table 1: distribution of cases according to type of seizures.

\begin{tabular}{|l|l|l|}
\hline Type of seizure & No. Of cases & Percentage \\
\hline Generalized seizures & 142 & $71 \%$ \\
\hline Focal seizures tonic & 58 & $29 \%$ \\
\hline $\begin{array}{l}\text { Generalized } \\
\text { clonic seizures }\end{array}$ & $69 \%$ \\
\hline Tonic seizures & 40 & $20 \%$ \\
\hline Myoclonic seizures & 16 & $8 \%$ \\
\hline Others & 6 & $3 \%$ \\
\hline
\end{tabular}

Neuroimaging was done in 36 cases (18\%) who were admitted with seizures. Neuroimaging had revealed abnormalities in 16 out of the 36 children (44.4\%) in whom it was performed.

Electroencephalogram (EEG) was done in 42 cases (21\%) children and had abnormal reports in $24(57.1 \%)$ of cases .

Table 2: distribution of cases according to etiology of seizures.

\begin{tabular}{|c|c|c|}
\hline Etiology & No. Of cases & Percentage \\
\hline Febrile Seizures & 79 & $39.5 \%$ \\
\hline $\begin{array}{cc}\text { CNS: } & \\
\bullet & \text { Meningitis } \\
\end{array}$ & 58 & $28 \%$ \\
\hline \begin{tabular}{ll}
\multicolumn{2}{l}{ Seizure disorder: } \\
- Idiopathic epilepsy \\
- & Cerebral palsy \\
- & Sturge \\
& syndrome
\end{tabular} & 24 & $12 \%$ \\
\hline Neurocysticercosis & 10 & $5 \%$ \\
\hline Encephalitis & 9 & $4.5 \%$ \\
\hline \begin{tabular}{cl}
\multicolumn{2}{l}{ Metabolic causes: } \\
- & Hypocalcaemia \\
- & hyponatremia \\
- & hypoglycaemia
\end{tabular} & 8 & $4 \%$ \\
\hline $\begin{array}{ll}\text { Miscellaneous: } \\
\text { - } \\
\text { Intracranial } \\
\text { - } \\
\text { hemorrhage } \\
\text { Brain tumors like } \\
\text { gliomas } \\
\text { Cyanotic congenital } \\
\\
\quad \text { heart disease with } \\
\text { hypoxic spells. } \\
\text { - } \quad \text { Subacute infarcts } \\
\end{array}$ & 12 & $6 \%$ \\
\hline
\end{tabular}

On basis of Etiology, febrile seizures were the most common diagnosis which included 79 cases $(39.5 \%)$, followed by CNS infections like meningitis (pyogenic/aseptic) which contributed 58 cases (28\%) of all, Seizure disorder like idiopathic epilepsy, cerebral palsy and Sturge Weber syndrome, contributing to 24 cases $(12 \%)$, Neurocysticercosis with $10(5 \%)$, encephalitis $9(4.5 \%)$ and Metabolic causes like hypocalcaemia, hyponatremia and 
hypoglycaemia comprised of $8(4 \%)$ cases. Rest other miscellaneous etiologies like intracranial hemorrhage, brain tumors like gliomas, cyanotic congenital heart disease with hypoxic spells, subacute infarcts etc. that accounted for remaining $12(6 \%)$ of cases.

Final outcome of patients revealed that $170(85 \%)$ patients got discharged without deficit, $8(4 \%)$ with deficits at discharge, $12(6 \%)$ went LAMA and were referred, and 10 (5\%) patients expired.

\section{Discussion}

In this present retrospective observational study hospital based study a total of 200 children were enrolled. Seizure occurrence was commonest in less than 5 yrs age group as compared to greater than 5 years with 79 (39.5\%) cases. In similarity to ours Singh RD et al also reported similar findings. They explained on basis that 6 months to 5 yrs age group seemed to be more susceptible because this is the age group which has high incidence of febrile seizures as well they are more prone to CNS infections and metabolic derangements. ${ }^{[8]}$

The most common seizures observed in our study were generalized seizures of which the most common subtype was Generalized tonic clonic seizures. Few other authors were also in consensus with our results. ${ }^{[8-11]}$

Febrile seizures were the most common etiology which included 79 cases $(39.5 \%)$ cases in our study mainly in children less than 5 years of age. earlier studies have also shown that Febrile seizures as one of the most common causes of seizure attack in children. ${ }^{[12-14]}$ also this was the commonest etiology (62\%) in the study by Chen et al, ${ }^{[9]}$ while it was $71 \%$ as found by Landfish et al. ${ }^{[15]}$ On contrary Singh RD et al reported CNS infections to be commonest cause of seizure in pediatric age group, followed by SOL, epilepsy, febrile seizures and metabolic causes. ${ }^{[8]}$

Final outcome of patients revealed that $85 \%$ patients got discharged without deficit, $4 \%$ with deficits at discharge, $6 \%$ went LAMA and were referred, and 5\% patients expired. CNS infection being the most common cause of death in our study while febrile seizures had the best outcome with all patients discharged without any deficits. Mortality rate during hospital course among children admitted with acute episode of seizure was similar with reports from other developing countries. ${ }^{[14]}$

Hence we can say that CNS infections need to be focused more because of highest morbidity and mortality. An attempt should be made to know the burden of causative organisms for CNS infections and preventive measures should be undertaken. Health care facilities should be prepared for emergency management of seizures with intensive care units to decrease mortality and morbidity.

\section{Conclusion}

We found CNS infections to be the most common etiology and a poor outcome. Acute episode of seizures is one of the commonest causes of hospitalization with high morbidity and mortality. Being a developing nation, strict measures to prevent infection can reduce the occurrence of seizures in children thus preventing long term neurological sequelae in children.

\section{References}

1. Kleigman RM, Stanton BM, St. Geme J, Schor NF, Behrman RE. Nelson textbook of pediatrics. 20th ed. Philadelphia (PA): Elsevier Saunders; 2015. Seizures in childhood; p. 2823.

2. Martindale JL, Goldstein JN, Pallin DJ: Emergency department seizure epidemiology. Emerg Med Clin North Am 2011 Feb, 29(1):15-27.

3. Hauser WA: The prevalence and incidence of convulsive disorders in children. Epilepsia 1994, 35(suppl 2):S1-S6.

4. Chen CY, Chang YJ, Wu HP: New-onset Seizures in Pediatric Emergency. Pediatr Neonatol 2010, 51(2):103-111

5. Fisher RS, Cross JH, French JA, Higurashi N, Hirsch E, Jansen FE, et al. Operational classification of seizure types by the International League Against Epilepsy: Position paper of the ILAE Commission for Classification and Terminology. Epilepsia. 2017;58:522-30

6. Pearce MS, Salotti JA, Little MP, McHugh K, Lee C, Kim KP, et al. Radiation exposure from CT scans in childhood and subsequent risk of leukaemia and brain tumours: a retrospective cohort study. Lancet. 2012;380:499-505.

7. Seizure classification [Internet]. [cited 2016 Mar 6]. Available from: https://www.epilepsydiagnosis.org/ seizure/seizure-classificationgroupoverview.html

8. Rupa Dalmia Singh, Shashank Suryavanshi. A hospital based study on clinicoetiological profile of seizures in children - a Kanpur (U.P., India) experience. International Journal of Contemporary Medical Research 2016;3(10):3003-3007

9. Chen C-Y, Chang Y-J, Wu H-P. New-onset seizures in pediatric emergency. Pediatr Neonatol. 2010;51:103-11.

10. Adhikari S, Sathian B, Koirala DP, Rao KS. Profile of children admitted with seizures in a tertiary care hospital of Western Nepal. BMC Pediatr. 2013;13:43.

11. Camfield PR, Camfield CS, Dooley JM, Tibbles J a. R, Fung T, Garner B. Epilepsy after a first unprovoked seizure in childhood. Neurology. 1985;35:1657-1657.

12. Martindale JL, Goldstein JN, Pallin DJ: Emergency department seizure epidemiology. Emerg Med Clin North Am 2011 Feb, 29(1):15- 27.

13. Hauser WA: The prevalence and incidence of convulsive disorders in children. Epilepsia 1994, 35(suppl 2):S1-S6.

14. Idro R, Gwer S, Kahindi M: The incidence, aetiology and outcome of acute seizures in children admitted to a rural Kenyan district hospital BMC Pediatr 2008, 8:5. http://www.biomedcentral.com/1471- 2431/8/5.

15. Santos MI, Nzwalo H, Monteiro JP, Fonseca MJ: Convulsive status epilepticus in the pediatric emergency department: five year retrospective analysis. Acta Med Port 2012, 25(4):203-206. 
Copyright: () the author(s), 2020. It is an open-access article distributed under the terms of the Creative Commons Attribution License (CC BY 4.0), which permits authors to retain ownership of the copyright for their content, and allow anyone to download, reuse, reprint, modify, distribute and/or copy the content as long as the original authors and source are cited.

How to cite this article: Jagannath HN. Evaluation of Clinical \& Etiological Profile of Children with Seizures. Asian J. Clin. Pediatr. Neonatol.2020;8(1):92-95.

DOI: dx.doi.org/10.47009/ajcpn.2020.8.1.22

Source of Support: Nil, Conflict of Interest: None declared. 